\title{
Propagation of Inflowing Urban Stormwater Pulses Through Reservoir Embayments
}

Megan Fork ( $\nabla$ megan.fork@gmail.com )

Cary Institute of Ecosystem Studies https://orcid.org/0000-0002-7789-3316

Ryan McManamay

Baylor University

James Heffernan

Duke University

\section{Research Article}

Keywords: impoundment, residence time, stormflow, urban stream, conductivity, stratification

Posted Date: October 21st, 2021

DOl: https://doi.org/10.21203/rs.3.rs-528727/v1

License: (1) This work is licensed under a Creative Commons Attribution 4.0 International License.

Read Full License

Version of Record: A version of this preprint was published at Urban Ecosystems on February 14th, 2022.

See the published version at https://doi.org/10.1007/s11252-022-01218-7. 


\section{Abstract}

Flashy hydrology and high solute loads in stormflow are well-studied effects of the built environment on urban streams. The physical and chemical interactions between inflowing stormwater of urban streams and their termination in large impoundments, however, is poorly understood. Determining the spatial distribution of urban stormwater in reservoirs is an important step in understanding the effects of the heat and contaminant loads in these systems, which provide multiple services for adjacent cities. Here, we show that signals of stormwater from a small urban stream can propagate more than $800 \mathrm{~m}$ from the stream mouth. Stormflow can also break down the thermal stratification that exists during non-storm periods. Because the relative volume of inflowing water relative to stored water in a reservoir embayment determines the distance stormwater propagates, management of both the urban landscape (which affects runoff volumes) and of reservoir water levels affects the spatial footprint of urban stormwater. These physical and chemical effects of stormwater may have significant implications for nutrient and pollutant transport through and biogeochemical reactions in reservoirs, as well as habitat for organisms and processing of organic matter and greenhouse gases in these dynamic ecosystems.

\section{Introduction}

Managing stormwater runoff is a challenge faced by urban areas globally. Proliferation of impervious surface area in urban landscapes increases the proportion of precipitation that become runoff, increasing the flashiness of hydrologic regimes (Walsh et al. 2005). Urban stormwater frequently also carries a wide range of pollutants and trash (Masoner et al. 2019). During high flows, pulses of stormwater are shunted downstream with little to no processing in stream channels (Raymond et al. 2016). However, reservoirs store water and inherently dampen peak flows (Fitzhugh and Vogel 2011), thereby increasing the residence time of hydrologic inputs and settlement of loads. Considering the fact that lakes or reservoirs occur every 1-5 km along smaller stream networks (Gardner et al. 2019), a likely fate of the pulse-shunt (sensu Raymond et al. 2016) of urban stormwater is ending up in a reservoir.

Reservoirs are generated by the impoundment of river to create an artificial lake. Reservoirs develop characteristically distinct zones, delineated by the presence and strength of stratification in the water column and the directionality of flow. The fluvial zone is characterized by a well-mixed water column, the lacustrine by stratification, and the transition zone by intermediate conditions including complex hydrodynamics as these distinct waters mix (Thornton et al. 1990). While this zonation typically refers to conditions along the mainstem river at the upstream end of the reservoir, similar shifts from lotic to lentic conditions occur as small streams flow into embayments (i.e., backwater "arms" of larger reservoirs caused by the drowning of tributary mouths).

Because transition zones between the lotic and lentic conditions in reservoirs balance substrate delivery from the watershed and sufficient residence time for biogeochemical transformation, they are good candidates to act as biogeochemical control points (sensu Bernhardt et al. 2017). Indeed, the transition zone between inflowing streams and open water lacustrine areas can be hotspots for methane emission 
(Beaulieu et al. 2016) and sediment oxygen demand (McCarthy et al. 2007). During storms, water with distinct physical and chemical characteristics (including sediment, nutrients, and pollutants derived from the landscape) is delivered to reservoirs (e.g. Fallon et al. 2002, Vanni et al. 2006). In urban streams, stormwater also carries heat (Somers et al. 2013) and metallic and organic contaminants (Masoner et al. 2019) in addition to nutrients, sediment, and other solutes (Walsh et al. 2005). These pulses of water with distinct chemical and physical properties have the potential to drive increases in rates of biogeochemical transformation. Yet, few studies have focused on using the distinct physicochemical composition of stormwater pulses to identify and characterize their propagation and attenuation through receiving reservoirs.

Quantifying the propagation of stormwater - the spatial footprint and timing of thermal and chemical changes that result from inflowing runoff from the landscape- is an important step in determining the ecological and human health impacts of stormwater pulses in reservoirs. Furthermore, better understanding of what influences the propagation of stormwater through reservoirs can help predict these impacts under changing precipitation regimes and under different management strategies.

In this paper, we use a combination of high frequency conductivity and temperature data collected at longitudinal transects in three reservoir embayments, spanning a gradient of watershed urbanization, in the southeastern US to show propagation of stormwater pulses through these systems and temperature destratification resulting from storms. We predicted that the signals of stormflow inputs to the reservoir would be visible as changes in conductivity and thermal destratification and that non-exclusive drivers of

these responses may be: a) the relative volume of incoming stormwater, b) rainfall volume/intensity, or c) strength of thermal stratification preceding the storm. Because greater impervious surface cover in urban watersheds generates more runoff per unit rainfall, we expected that physicochemical signals of stormwater would be more pronounced and travel further in embayments with more urbanized watersheds.

\section{Methods}

\section{Site description}

We collected hydrologic, chemical, and thermal data in three reservoir embayments in east Tennessee that received flow from streams with watershed land embayments ranging from 8-91\% developed (based on NLCD 2011 land cover; Table S1 and Fig. 1). The embayments in our study comprised the primarily lentic water located between the mouths of streams and the mainstem reservoir. The embayment located at Walker Branch (WB) is in the Melton Hill Reservoir, a run-of-river reservoir on the Clinch River completed in 1963, and the stream drains a 587 ha watershed that is $8 \%$ developed. The embayments located at Taylor Branch (TB) and Fourth Creek (FC) are part of the Fort Loudon Reservoir, the uppermost dam on the Tennessee River. TB drains a 1307 ha watershed with $46 \%$ development, while FC drains the largest (2523 ha) and most developed (91\%) watershed. Both of the dams produce 
hydroelectric power and are operated by the Tennessee Valley Authority (www.tva.gov), which maintains daily records of reservoir water surface elevation.

\section{Field measurements}

We deployed three buoys at each of the three embayments from July 2015 to September 2016 (Fig. 1): Buoy 1 was located at the mouth of the stream, Buoy $2300 \mathrm{~m}$ from the mouth of the stream, and Buoy 3 $800 \mathrm{~m}$ from the mouth of the stream. Each buoy included two temperature loggers (Onset HOBO UA-00264) mounted approximately $25 \mathrm{~cm}$ below the water surface and approximately $25 \mathrm{~cm}$ above the sediment (measuring temperature of the epilimnion and hypolimnion, respectively) and one conductivity logger (Onset HOBO U24-001) mounted approximately $30 \mathrm{~cm}$ above the sediment. We visited the buoys and streams every 2-8 weeks to download data and to clean and maintain equipment.

The loggers collected data at five-minute intervals throughout the deployment period (July 2015 through September 2016) excepting periods of equipment loss or failure. In November 2015, additional temperature loggers were added at depths of 0.5 and $1 \mathrm{~m}$ (depth permitting) that logged every $30 \mathrm{~m}$ (Onset HOBO UA-002-08) to complement higher frequency measurements of temperature at the surface and bottom of the water column.

During each visit, we collected water samples from the top and bottom of the water column at each buoy location for analysis of total dissolved nitrogen (TDN) and recorded a depth profile of temperature, conductivity, and dissolved oxygen using a water quality sonde (YSI 6920 fitted with 6560 Temperature/Conductivity sensor). We also collected bathymetry data at each of the three reservoir embayments in August 2015 using a sonar depth finder (Humminbird PiranhaMAX 150) and GPS application (GeoTracker version 2.2.2).

Discharge timeseries were available for WB and FC. At WB, 15-minute discharge data were collected from the weir located on the west fork and historic data were used to predict flow at the east fork to estimate total flow from Walker Branch into the Melton Hill Reservoir. The City of Knoxville provided 15-minute discharge and rainfall data for FC from a station located at Walden Dr. Hourly rainfall in the TB and WB catchments were estimated from NOAA rainfall gages located at McGhee Tyson Airport (Station ID 13891) and Oak Ridge (Station ID 53868), respectively.

\section{Data processing and analysis}

We used ANOVA to compare baseflow data among buoys and streams at different sites and paired t-tests to compare surface and bottom measurements of chemistry and dissolved oxygen at baseflow conditions. These comparisons allowed us to assess differences among background chemistry and stratification among embayments. All analyses were performed using R version 3.4.3 (R Development Core Team 2012).

\section{Reservoir volume and logger depth}


We determined the volume of water between the stream mouth and the reservoir embayment crosssection at each buoy ("uplake volume") using measured bathymetry and linear interpolation of water depth measurements at each buoy during field visits and using hourly reservoir water surface elevation reported by TVA. Point bathymetry data were interpolated by inverse distance weighting in ArcMap version 10.4.1. We then used bathymetry rasters and modeled water depth to calculate the uplake volume for each buoy using the Surface Volume tool. We also used relationships between measured water depth at each buoy and reported water surface elevation to determine changes in the depth of loggers resulting from changes in water depth over the course of the study. We used these corrected values to omit events for which the top and bottom temperature loggers were within $10 \mathrm{~cm}$ of one another from the analysis of thermal stratification.

\section{Processing of logger data}

Logger data were downloaded and processed using HOBOware Pro (version 3.7.x). Specifically, pressure data were converted to water level using the Barometric Compensation Assistant and conductivity data were converted to specific conductance using the Conductivity Assistant (per ISO 7888:1985 with factory calibration). With the exception of this processing in HOBOware Pro, all logger data were processed and analyzed using R. After omitting a 15-minute window from the beginning and end of each download file to remove data collected when the loggers were being handled, the data for each logger were stitched together into a single time series, and obvious outliers and dry periods were deleted to generate semicontinuous time series. For each semi-continuous time series, we estimated the "background" conductivity by the Sensitive Nonlinear Iterative Peak algorithm (with a second order filter) using the R package "Peaks" (Morhac 2012), which allowed us to characterize the deflection in the conductivity signal associated with storms.

From the logger time series, we identified storms for which: a) an event rainfall was $>2 \mathrm{~mm}, \mathrm{~b}$ ) we observed a distinct depression in the conductivity at buoy 1 , and c) we had complete records for conductivity and temperature at each of the three buoys deployed at the site. These events were then isolated for further analysis. We clipped individual storms from the time series by setting start times 3 hours before the first one-hour window in which the coefficient of variation in a one-hour rolling window of 5-minute conductivity at buoy 1 exceeded $5 \%$ and end times that coincided with a return to baseline conductivity (i.e. difference between measured and background conductivity $<5 \%$ of maximum difference for the storm) at all three buoys. For events in which the signal of conductivity or flow had not reset to the baseline before another storm, we clipped the entire sequence of storms together and considered them as a single event for the purpose of the analyses. A minority of cases ( $n=4$ of 31 for FC, $n=10$ of 34 for WB, $\mathrm{n}=2$ of 24 for TB) were particularly noisy periods in time series and prevented our clipping algorithm from identifying time points that met these criteria. In these cases, we chose event start or end times by visually examining time series plots at each of the buoys and selecting time points that best represented the above criteria.

\section{Analysis of storm conductivity signal propagation/attenuation}

Page 5/20 
To characterize how pulses of stormwater delivered by streams are propagated and attenuated once they reach reservoirs, we analyzed characteristics of the conductivity signal during storms. For each storm, we calculated the maximum displacement (i.e. the Z-scored "inverse" peak height of the conductivity signal, henceforth "storm conductivity minimum", Figure S1) as a proxy for the magnitude of change in water chemistry associated with a storm pulse. We also calculated the total area between the measured signal and background conductivity (i.e., the time-integrated area between the storm conductivity signal and the background, henceforth "storm conductivity area", Figure S1), which we consider a proxy for the stormwater volume passing the buoy.

We used linear multiple mixed effects regression to identify predictors of storm conductivity area and storm conductivity minimum. Our list of potential predictors included: meteorological season, maximum

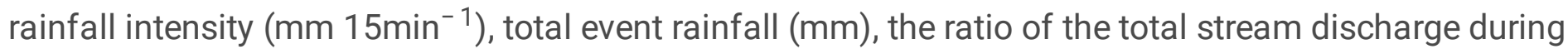
the storm to the volume of water uplake of the buoy (SW:ResVolume, available for sites FC and WB only). After log-transforming predictors with highly skewed distributions, we removed highly correlated covariates $(r>0.8)$ from the set of predictor variables. We then used the R package "nIme" (Pinheiro et al. 2017) to fit the form of linear mixed-effects regression models (chosen by Bayesian Information Criterion, BIC). When the best model form did not include random effects, we used the R package "leaps" to select the parameters for best-fit final model (Lumley and Miller 2017).

To more directly investigate propagation of conductivity signals through the reservoir, we also modeled the storm conductivity area at buoys 2 and 3 as a function of the storm conductivity area at buoy 1 . Because the conductivity of stormwater was distinct from that of reservoir water, similar storm conductivity areas between buoy 1 and downlake buoys implies transport of stormwater from between the buoys. Where storm conductivity area at downlake buoys is less than at buoy 1 , we interpreted as either attenuation of the stormwater in the reservoir or flow along an alternative path that did not intersect the buoy. We fit a linear mixed effects regression model to relate the storm conductivity area at downlake buoys to that at buoy 1 . We then used simple linear regression to explore relationships between the residuals of this model to our set of predictor variables.

\section{Analysis of thermal destratification}

We also analyzed the probability of thermal destratification during storm events. We defined destratification as a difference of $<1^{\circ} \mathrm{C}$ between temperature readings at the top and bottom of the water column following a period of a difference $>11^{\circ} \mathrm{C}$ (Woolway et al. 2014), and used this binary response in mixed effects logistic regression to predict the probability of thermal destratification at buoys 2 and 3 .

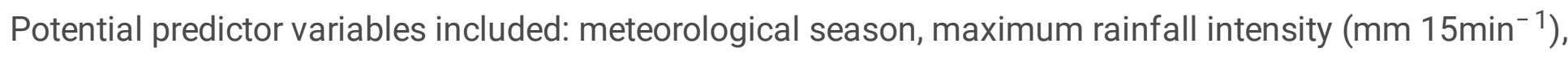
total event rainfall $(\mathrm{mm}), \mathrm{SW}$ :ResVolume, and mean air temperature for the 5 hours preceding the start of rainfall (C). After log-transforming predictors with highly skewed distributions, we removed highly correlated covariates ( $r>0.8)$ from the set of predictor variables. We then used the R package "Ime4" (Bates et al. 2015) to fit mixed effects logistic regression models and used BIC to select the best-fit final model. 


\section{Results}

\section{Baseflow conditions among sites}

Baseflow physical and chemical characteristics of the streams draining into the reservoir embayments differed among our three sites. Mean water temperature in FC tended to be higher than the other two streams, but this difference was not statistically significant $(p=0.07$; Table S1). Mean baseflow conductivity was significantly different among the three streams, following the pattern in urban development among catchments, with $\mathrm{FC}>\mathrm{TB}>\mathrm{WB}(\mathrm{p}<0.0001$; Table $\mathrm{S} 1)$. Baseflow dissolved oxygen (DO) concentration was significantly lower in TB than FC $(p=0.003)$, while baseflow total dissolved nitrogen (TDN) was significantly lower in WB than the other two streams $(p=0.0001$; Table S1).

Over the 16 months of our study, we observed significant variability in the water depths at our sensor buoys (Table S1), particularly in the Fort Loudon Reservoir (FC and TB), that were primarily the result of changes in reservoir stage. Water depths were lowest in winter and varied by more than $1 \mathrm{~m}$ over the course of the study, resulting in large differences in the wetted area and upstream volume of reservoir embayments among seasons.

While the water column at our buoys was generally well-oxygenated (for sites $<2 \mathrm{~m}$ deep, Table $\mathrm{S} 1$ ), mean DO concentrations were significantly higher in surface vs. bottom waters $(p<0.0001)$. Mean TDN concentrations were slightly lower in surface vs. bottom waters $(p=0.048)$. Surface DO concentrations tended to be greater at buoys 2 and 3 vs. buoy 1 (i.e. further from the stream mouth; $p<0.0001$ ), probably because these sites were more open and phytoplankton experienced less shading. Bottom DO concentrations tended to be lower at buoys FC1 and WB3 than others $(p<0.0001)$, likely because these sites were deepest and the only sites that displayed distinct DO stratification over the course of the study. Neither surface nor bottom TDN concentrations were different among buoys or sites.

We also used sensor data to characterize temperature and conductivity at the buoys during non-storm conditions (Table S1). Conductivity during non-storm periods was higher in fall and winter than in spring and summer $(p<0.0001)$, and differed among sites with FC > TB $>W B(p<0.0001)$. During non-storm periods, mean surface and bottom water temperatures were significantly different $(p<0.0001)$, with bottom waters a mean of $3.2^{\circ} \mathrm{C}$ cooler than surface over the course of the study. The temperature difference between surface and bottom water varied significantly among seasons $(p<0.0001)$ with a mean difference of $5.4^{\circ} \mathrm{C}$ in summer and only $0.3^{\circ} \mathrm{C}$ in winter.

\section{Storm conductivity signals}

Storms produced identifiable deflections in conductivity and thermal destratification of the reservoir that in many cases propagated through the entire $800 \mathrm{~m}$ of the study areas (Fig. 2). The storm conductivity minimum was significantly smaller for stormwater pulses that reached buoy 3 as compared to those at buoys $2(p=0.048)$ and $1(p<0.0001)$. Storm conductivity area did not differ significantly among buoys $(p=0.19)$. 
Across sites, storms with larger relative runoff volume produced greater relative decreases in conductivity and this relationship was consistent among sites (i.e., the best model did not include site or buoy as random effects). The storm conductivity minimum during storms was positively related to the natural logtransformed $S W$ :ResVolume $(p<0.0001)$. The model also included a positive interaction between season, $S W: R e s V o l u m e$, and the maximum rainfall intensity (with slightly greater slopes in spring and summer relative to other seasons; Table S2).

The storm conductivity area among events at buoys 2 and 3 was best predicted by a simple linear regression with SW:ResVolume, which described $77 \%$ of the variation in storm conductivity area among storms in the pooled data (Fig. 3; Table S3). Storm conductivity area was greater at higher values of SW:ResVolume. The best model did not include any random effects (i.e., slopes and intercepts did not differ among streams with different watershed landcover), nor was season an important predictor. To estimate the size of reservoir required to attenuate storm conductivity signals for a storm of a given size, we calculated the SW:ResVolume associated with a storm conductivity area of $5 \mu S^{*}$ (i.e., about onehalf of the smallest values observed in our dataset). This "threshold" value of SW:ResVolume needed to attenuate the conductivity of stormwater pulses in reservoirs is $4.52^{\star} 10^{-6}$.

The relationship between storm conductivity area at buoys 2 and 3 vs. at buoy 1 among sites was best described by a model with random slopes and intercepts for each buoy (Fig. 3; Table S4). The slopes for buoys in embayments with urbanized landscapes (FC and TB, range: $0.80-0.84$ ) tended to be greater than the slopes for buoys in the embayment downstream of forest (WB2 $=0.73$, WB3 $=0.53$ ), suggesting the storm conductivity area at buoys 2 and 3 in these sites is more similar to that at buoy 1 for the embayments with more urbanized watersheds.

\section{Thermal destratification during storms}

Among pooled storm observations from buoys 2 and 3 at all sites, we observed thermal destratification during storms in $65.0 \%$ of events (89 of 137 ). The probability of thermal destratification among all sites was best predicted by a logistic regression model without random effects among sites and included mean air temperature in the 5 hours preceding the onset of rainfall, total rainfall over the storm, and the stored lentic volume (Table S5). The probability of destratification was negatively related to mean air temperature and stored lentic volume, and positively related to the total rainfall.

\section{Discussion}

Our analysis of high-frequency sensor data from storms in three reservoir embayments shows that pulses of incoming stormflow can be readily detected, induce significant changes to the physical and chemical conditions, and frequently propagate $800 \mathrm{~m}$ or more through reservoir embayments. The chemical effects of stormwater pulses were more pronounced in embayments draining urbanized streams, with the influence of stormwater principally governed by the relative volume of inflowing stormwater relative to the volume of lentic water stored in the reservoir. In contrast, the persistence of thermal stratification of the water column during storms did not depend on the size or intensity of storm. Instead, the probability of 
destratification during storms depended primarily on the mean air temperature preceding the storm, with destratification more likely when air temperatures were colder.

\section{Conductivity signals of stormwater pulses and propagate further in urbanized sites}

The relative volume of stormwater to lentic receiving water is was an important predictor of the magnitude of its effects. We found that a SW:ResVolume of $4.52 * 10^{-6}$ is needed to attenuate the conductivity signal of stormwater pulses in reservoirs. This means that for a one-inch $(2.54 \mathrm{~cm})$ rainstorm in the urbanized Fourth Creek watershed of Knoxville, TN, which yields an approximate total runoff volume of $199,100 \mathrm{~m}^{3}$, would need a reservoir volume of $4.406^{\star} 10^{10} \mathrm{~m}^{3}$ (more than the storage capacity of the entire reservoir) to attenuate the physicochemical signal of stormwater.

The landcover of watersheds was related to the characteristics of stormwater effects in receiving reservoirs. At more urbanized sites (FC and TB), the storm conductivity area was similar among buoys for a given storm, suggesting that much of the volume of stormwater runoff can be transmitted large distances through the reservoir. Although the magnitude of the storm conductivity minimum decreases and the area becomes broader and shallower as stormwater pulses move downlake (Fig. 2), the consistency in storm conductivity area among buoys suggests that these urban stormwater pulses travel as coherent slugs through the receiving embayments. In contrast, stormwater pulses observed at the mouth of WB were either partially attenuated before reaching buoys 2 and 3, or followed flowpaths that did not intersect with our sensors. Flashier hydrology in urban as opposed to non-urban streams may facilitate the shunting of stormwater runoff through impoundments. However, it is impossible for us to differentiate whether differences in storm response among our study sites is the result of landcover in the three catchments or arises from the unique morphology of each site (drainage ratio, bathymetry, etc.) or, most likely, the combination of these factors. Additional research on the effects of sotrmwater pulses in receiving reservoirs will help to distinguish the effects of watershed landcover vs. reservoir morphometry.

Residuals of the relationship of storm conductivity area between downlake buoys and the stream mouth were smaller when SW:ResVolume was high, indicating that the volume of stormwater moving past buoys is more similar among buoys during larger vs smaller storms. This suggests that during lager storms these embayments are dominated by directional flow (i.e., act more lotic) and coherent pulses of stormwater are advected through the flooded channel toward the reservoir mainstem.

\section{Seasonal differences in storm-driven destratification}

While urbanization can significantly increase water temperature, and particularly stormflow temperature, in streams (Somers et al. 2013), we did not find differences among watersheds in the destratification associated with incoming stormflow pulses. Instead, preceding air temperature, total rainfall, and the volume of stored water were the most important predictors of whether incoming stormflow pulses would result in thermal destratification of the receiving reservoir embayment. 
Observed variation in temperature differences between surface and bottom waters may indicate differences in the strength of stratification among seasons. During summer, thermal stratification is strong and may be more resistant to the flow-driven destratification during storms. This, in turn, may suggest different hydrodynamics of incoming flow (e.g. underflow of incoming water beneath warmer, less dense water stored in the reservoir; Thornton et al. 1990) in summer as opposed to winter, when stormflow may be more likely to fully destratify and mix the water column. We also found that storms were more likely to result in destratification when there was less water stored in the reservoir, i.e., when embayments were shallower. Because thermal stratification of the water column (and related changes in deepwater dissolved oxygen concentration) is an important control on processes including greenhouse gas emission (Deemer et al. 2016) and internal nutrient loading (Mortimer 1941), seasonal differences in destratification likelihood have implications for reservoir carbon balance and productivity.

\section{Management of urban watersheds and reservoirs}

Stormwater pulses are likely to exert expanding influence on reservoir hydrodynamics and chemistry owing to ongoing changes in land use and management, climatic change, and responses of reservoir management to these drivers. Our analysis points to two main categories of controls on the propagation of the acute effects of stormwater pulses through reservoir embayments: the "signal strength" of incoming storms (runoff volume and intensity of storm) and the "resistance" of the reservoir (volume of stored water and strength of thermal stratification). Ongoing changes in climate, land use, and management responses will alter incoming storms and the resistance of reservoirs (Hayes et al. 2017), with the likely outcome of these changes being increases in the magnitude and spatial footprint of the effects of stormwater pulses. Among the reservoir embayments we studied, pulses of stormwater were larger and propagated further in the reservoir embayments draining catchments with more urban development. Streams draining urbanized watersheds have higher runoff ratios (i.e. a greater proportion of rainfall becomes streamflow) than non-urban streams as a result of higher imperviousness (Dunne and Leopold 1978; Walsh et al. 2005), meaning increased signal strength for storms in urban watersheds. Given the strong influence of SW:ResVolume on propagation of stormwater pulses, we expect urbanization would increase the propagation of stormwater pulses through receiving reservoirs by generating a greater volume of stormwater for a given rainfall.

In our study, SW:ResVolume was a highly important predictor of the propagation of storm signals, and both terms in this ratio are subject to influence by human activity and decision-making. First, stormwater management affects the magnitude of incoming stormwater pulses. Impervious surfaces associated with urbanization increase the runoff ratio and thus the volume of stormwater pulse resulting from a rainstorm. Stormwater control measures that promote infiltration or detention reduce the total volume and intensity of stormwater pulses (e.g., Hopkins et al. 2019), thereby reducing the magnitude and spatial footprint of physicochemical signals of stormwater pulses in receiving waters. The volume of water stored in the reservoir, the denominator of this ratio, is also subject to the outcomes of human decision making. Water level at the dam in these reservoirs varied by more than $2 \mathrm{~m}$ over the course of our study, resulting in large differences in the amount of water stored in reservoir embayments and driving 
considerable variation in SW:ResVolume. As such, reservoir management can be an important driver of propagation or attenuation of incoming storm pulses. The construction, management, and removal of impoundments (including stormwater ponds and detention basins) along an urban stream network will also affect propagation of stormwater signals. The effect of multiple impoundments in a connected network on the size and propagation of stormwater temperature and chemistry signatures deserves further attention.

Finally, climate change will likely affect the characteristics of storms and the responses of reservoirs to them. The amount of precipitation delivered by individual storms is predicted to increase in many parts of the United States (USGCRP 2017). Since storms of larger precipitation volume and greater intensity drive bigger transient changes in reservoir chemistry and higher destratification probability, we may expect more frequent and pronounced lotic conditions in reservoirs. This, in turn, suggests propagation of stormwater and the constituents it carries (e.g. nutrients, pollutants, organic matter) further distances through reservoirs during storms. In contrast, warmer temperatures that result from climate change will likely increase the strength of thermal stratification, decreasing the likelihood of destratification resulting from stormwater pulses. More persistent stratification may facilitate shunting of stormwater, as inflowing water will have less interaction with water of different density (Thornton et al. 1990). Less frequent destratification will also mean less mixing between epi- and hypolimnetic waters, which could generate or exacerbate hypoxic conditions and promote phosphorus availability in the cool, deeper waters. Given increasing urbanization and climate change, the footprint of inflowing stormwater in reservoirs is likely to increase while storm-driven destratification of the water column may be less likely.

\section{Implications for reservoir ecosystem function and services}

Incoming stormwater pulses can have significant impacts on the water quality and ecology of receiving reservoirs. Vanni et al. (2006) described the discharge of inflowing streams as the "master variable" determining nutrient limitation status of reservoir phytoplankton, and showed that storms drive a shift from nutrient- to light-limitation. Because stormwater tends to deliver both nutrients and sediment, stormwater pulses can increase the nutrient availability at the same time as reducing light availability. Furthermore, storm pulses may flush phytoplankton from the reservoir or mix them out of the epilimnion as the water column destratifies, reducing competition for nutrients and possibly temporarily increasing the favorability of conditions for denitrification. Storm pulses in reservoirs may also change the structure of phytoplankton communities (Edson and Jones 1988).

Stormwater pulses in reservoirs have implications not only for their ecology but also for their functionality as water resources for human use. In some cases, storms can trigger cyanobacterial blooms that release toxins into drinking water sources (Falconer and Humpage 2005). Dissolved organic carbon concentrations and loads tend to increase at higher flows in many catchments (e.g. Butturini et al., 2006; Dhillon \& Inamdar, 2013; Hook \& Yeakley, 2005; Inamdar \& Mitchell, 2006; Raymond \& Saiers, 2010) and can be transported to drinking water reservoirs, interfering with water treatment through the production of disinfection by-products (Leenheer 2004). Fallon et al. (2002) showed that pulses of the herbicides atrazine and deethylatrazine moved through a Kansas reservoir in a distinct pulse following a period of 
high rainfall. Storms also transport sediment to reservoirs (Knowlton and Jones 1995; Vanni et al. 2006). In addition to interfering with water clarity and the light environment, sediment loads are associated with high loads of pathogens (Kistemann et al. 2002) that may then move through reservoirs in distinct, coherent pulses (Brookes et al. 2005).

\section{Conclusions}

The empirical approach used in this study demonstrates that inflowing and stored volumes of water, which can be inferred from relatively straightforward and easy to collect measurements of water surface elevation, can predict changes in conductivity and stormwater propagation that result from stormwater pulses. Likewise, we found that the air temperature, which is widely and easily collected, was the best predictor for whether stormwater pulses will result in destratification of the receiving water column, across a range of watershed landcover. Because these measures of stormwater effects on reservoirs are widely available, they have the potential to be incorporated explicitly and even quantitatively into reservoir design and management decisions.

Human choices regarding management of both urban watersheds and reservoir water levels affects the magnitude and spatial footprint of stormwater pulses in reservoirs. Climate change will likely also drive increases in the magnitude and intensity of storms and decreases in the volume of water stored in reservoirs (as a result of drought and precautionary flood management); our data suggest that such changes would increase the propagation of storm pulses through reservoirs. However, warmer temperatures resulting from climate change may also strengthen stratification, decreasing the likelihood of storm-driven destratification events. These storm-driven changes to reservoirs have the potential to alter their physical, chemical, and biological structure beyond the duration of the storm.

\section{Declarations}

Funding: This work was funded through a Graduate Opportunities (GO!) Fellowship awarded to MLF in association with a Laboratory Directed Research and Development Project at Oak Ridge National Laboratory. RAM was supported by the U.S. Department of Energy, Office of Science, as part of research in MultiSector Dynamics, Earth and Environmental System Modeling Program.

Conflicts of interest/competing interests: The authors declare no conflicts of interest.

Availability of data and material (data transparency): Upon acceptance, data will be made available via the Hydroshare repository (https://www.hydroshare.org/).

Code availability (software application or custom code): Upon acceptance, analytical code will be made available via the Hydroshare repository (https://www.hydroshare.org/).

Authors' contributions: All authors contributed to the conception, approach, and data collection for the study. RAM generated maps for Figure 1. MLF analyzed data and wrote the manuscript with contributions 
from the other authors.

Acknowledgements: The US Coast Guard provided useful maps and ensured the placement of monitoring buoys, and water access was kindly provided by Dr. and Mrs. Lundin and Mr. and Mrs. Spivey. Thank you to Cliff Mann, who compiled and shared precipitation and flow data collected at Fourth Creek by the City of Knoxville. We thank Charlotte Brown, Laurel Christian, Chelsea Clifford, John Gardner, Brooke Hassett, Jon Hathaway, Michael Jones, Makenzie Read, and Payton Smith for their essential assistance with field work and lab analyses. We thank Martin Doyle, John Gardner for valuable discussions about these ideas and acknowledge Robert Payne and two anonymous reviewers for helpful comments on a previous version of this manuscript.

\section{References}

1. Bates D, Mächler M, Bolker B, Walker S (2015) Fitting Linear Mixed-Effects Models Using \{lme4\}. J Stat Softw 67:1-48. doi: 10.18637/jss.v067.i01

2. Beaulieu JJ, McManus MG, Nietch CT (2016) Estimates of reservoir methane emissions based on a spatially balanced probabilistic-survey. Limnol Oceanogr 61:S27-S40. doi: 10.1002/Ino.10284

3. Bernhardt ES, Blaszczak JR, Ficken CD, et al (2017) Control Points in Ecosystems: Moving Beyond the Hot Spot Hot Moment Concept. Ecosystems 20:665-682. doi: 10.1007/s10021-016-0103-y

4. Brookes JD, Hipsey MR, Burch MD, et al (2005) Relative value of surrogate indicators for detecting pathogens in lakes and reservoirs. Environ Sci Technol 39:8614-8621. doi: 10.1021/es050821+

5. Butturini A, Francesc G, Jérôme L, et al (2006) Cross-site comparison of variability of DOC and nitrate c-q hysteresis during the autumn-winter period in three Mediterranean headwater streams: A synthetic approach. Biogeochemistry 77:327-349. doi: 10.1007/s10533-005-0711-7

6. Deemer BR, Harrison JA, Li S, et al (2016) Greenhouse Gas Emissions from Reservoir Water Surfaces: A New Global Synthesis. Bioscience 66(11): doi: 10.1093/biosci/biw117

7. Dhillon GS, Inamdar S (2013) Storm event patterns of particulate organic carbon (POC) for large storms and differences with dissolved organic carbon (DOC). Biogeochemistry 118:61-81. doi: 10.1007/s10533-013-9905-6

8. Dunne T, Leopold LB (1978) Water in Environmental Planning. W.H. Freeman \& Co., New York

9. Edson JJ, Jones RC (1988) Spatial, temporal, and storm-runoff-related variations in phytoplankton community structure in a small, suburban reservoir. Hydrobiologia 169:353-362. doi: 10.1007/BF00007558

10. Falconer IR, Humpage AR (2005) Health Risk Assessment of Cyanobacterial (Blue-green algal) Toxins in Drinking Water. Int J Environ Res Public Health 2:43-50. doi: 10.3390/ijerph2005010043

11. Fallon JD, Tierney DP, Thurman EM (2002) Movement of atrazine and deethylatrazine through a midwestern reservoir. J Am Water Work Assoc 94:54-66

12. Fitzhugh TW, Vogel RM (2011) The impact of dams on flood flows in the United States. River Res Appl 27:1192-1215. doi: 10.1002/rra.1417

Page $13 / 20$ 
13. Gardner JR, Pavelsky TM, Doyle MW (2019) The abundance, size, and spacing of lakes and reservoirs connected to river networks. Geophys Res Lett 0-2. doi: 10.1029/2018GL080841

14. Hayes, NM, Deemer BR, Corman JR, Razavi NR, Strock KE. (2017) Key differences between lakes and reservoirs modify climate signals: A case for a new conceptual model. Limnology and Oceanography Letters 2(2): 47-62. doi: 10.1002/lol2.10036

15. Hook A, Yeakley J (2005) Stormflow dynamics of dissolved organic carbon and total dissolved nitrogen in a small urban watershed. Biogeochemistry 75:409-431. doi: 10.1007/s

16. Hopkins KG, Bhaskar AS, Woznicki S, Fanelli R (2019) Changes in event-based streamflow magnitude and timing after suburban development with infiltration-based stormwater management. Hydrol Process. doi: 10.1002/hyp.13593

17. Inamdar SP, Mitchell MJ (2006) Hydrologic and topographic controls on storm-event exports of dissolved organic carbon (DOC) and nitrate across catchment scales. Water Resour Res 42:W03421. doi: 10.1029/2005WR004212

18. Kistemann T, Claßen T, Koch C, et al (2002) Microbial Load of Drinking Water Reservoir Tributaries during Extreme Rainfall and Runoff. Appl Environ Microbiol 68:2188-2197. doi: 10.1128/AEM.68.5.2188

19. Knowlton MF, Jones J (1995) Temporal and spatial dynamics of suspended sediment, nutrients, and algal biomass in Mark Twain Lake, Missouri. Arch Hydrolbiol 135:145-178

20. Leenheer JA (2004) Comprehensive assessment of precursors, diagenesis, and reactivity to water treatment of dissolved and colloidal organic matter. Water Sci Technol Water Supply 4:1-9

21. Lumley T, Miller A (2017) leaps: Regression Subset Selection

22. Masoner JR, Kolpin DW, Cozzarelli IM, et al (2019) Urban Stormwater: An Overlooked Pathway of Extensive Mixed Contaminants to Surface and Groundwaters in the United States. Environ Sci Technol 53:10070-10081. doi: 10.1021/acs.est.9b02867

23. McCarthy MJ, Gardner WS, Lavrentyev PJ, et al (2007) Effects of Hydrological Flow Regime on Sediment-water Interface and Water Column Nitrogen Dynamics in a Great Lakes Coastal Wetland (Old Woman Creek, Lake Erie). J Gt Lakes Res 33:219-231. doi: 10.3394/0380-1330(2007)33

24. Morhac M (2012) Peaks: Peaks

25. Mortimer CH (1941) The Exchange of Dissolved Substances Between Mud and Water in Lakes. J Ecol 29:280. doi: 10.2307/2256395

26. Pinheiro J, Bates D, DebRoy S, et al (2017) \{nlme\}: Linear and Nonlinear Mixed Effects Models 27. R Development Core Team (2012) R: A language and environment for statistical computing. R Foundation for Statistical Computing, Vienna, Austria

28. Raymond PA, Saiers JE (2010) Event controlled DOC export from forested watersheds. Biogeochemistry 100:197-209. doi: 10.1007/s10533-010-9416-7

29. Raymond PA, Saiers JE, Sobczak W V. (2016) Hydrological and biogeochemical controls on watershed dissolved organic matter transport: Pulse-shunt concept. Ecology 97:. doi: 10.1890/14- 
1684. 1

30. Somers K a., Bernhardt ES, Grace JB, et al (2013) Streams in the urban heat island: spatial and temporal variability in temperature. Freshw Sci 32:309-326. doi: 10.1899/12-046.1

31. Thornton KW, Kimmel BL, Payne JT (1990) Reservoir Limnology: Ecological Perspectives. John Wiley \& Sons, Inc.

32. USGCRP (2017) Climate Science Special Report: Fourth National Climate Assessment, Volume I. U.S. Global Change Research Program, Washington, DC, USA

33. Vanni MJ, Andrews JS, Renwick WH, et al (2006) Nutrient and light limitation of reservoir phytoplankton in relation to storm-mediated pulses in stream discharge. Arch Hydrolbiol 167:421445. doi: 10.1127/0000-0000/0000/0000-0000

34. Walsh CJ, Roy AH, Feminella JW, et al (2005) The urban stream syndrome: current knowledge and the search for a cure. J North Am Benthol Soc 24:706-723

35. Woolway RI, Maberly SC, Jones ID, Feutchtmayr H (2014) A novel method for estimating the onset of thermal stratification in lakes from surface water measurements. Water Resour Res 50:5375-5377. doi: 10.1002/2013WR014979.Reply

\section{Figures}



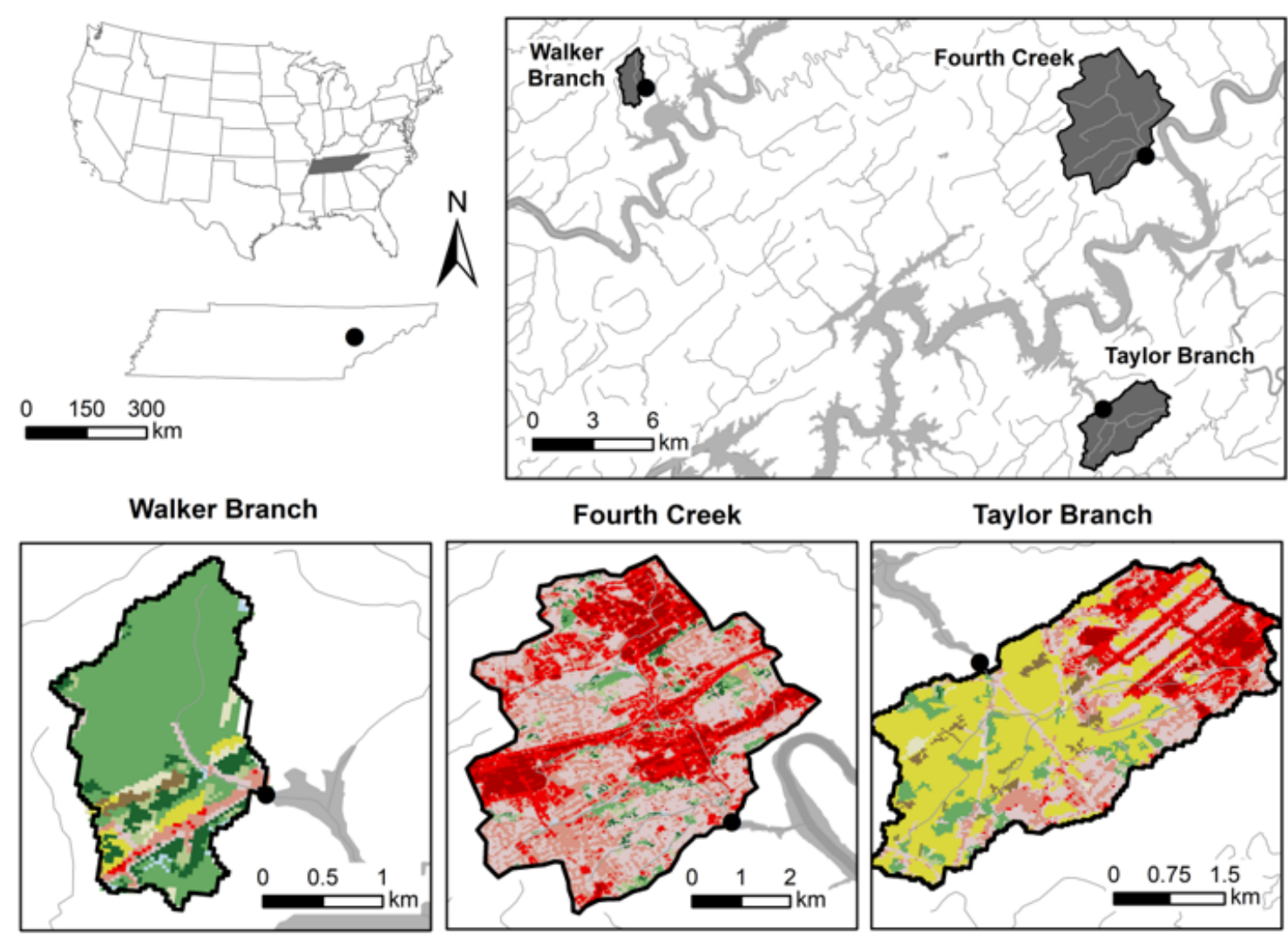

NLCD

\section{Classes}
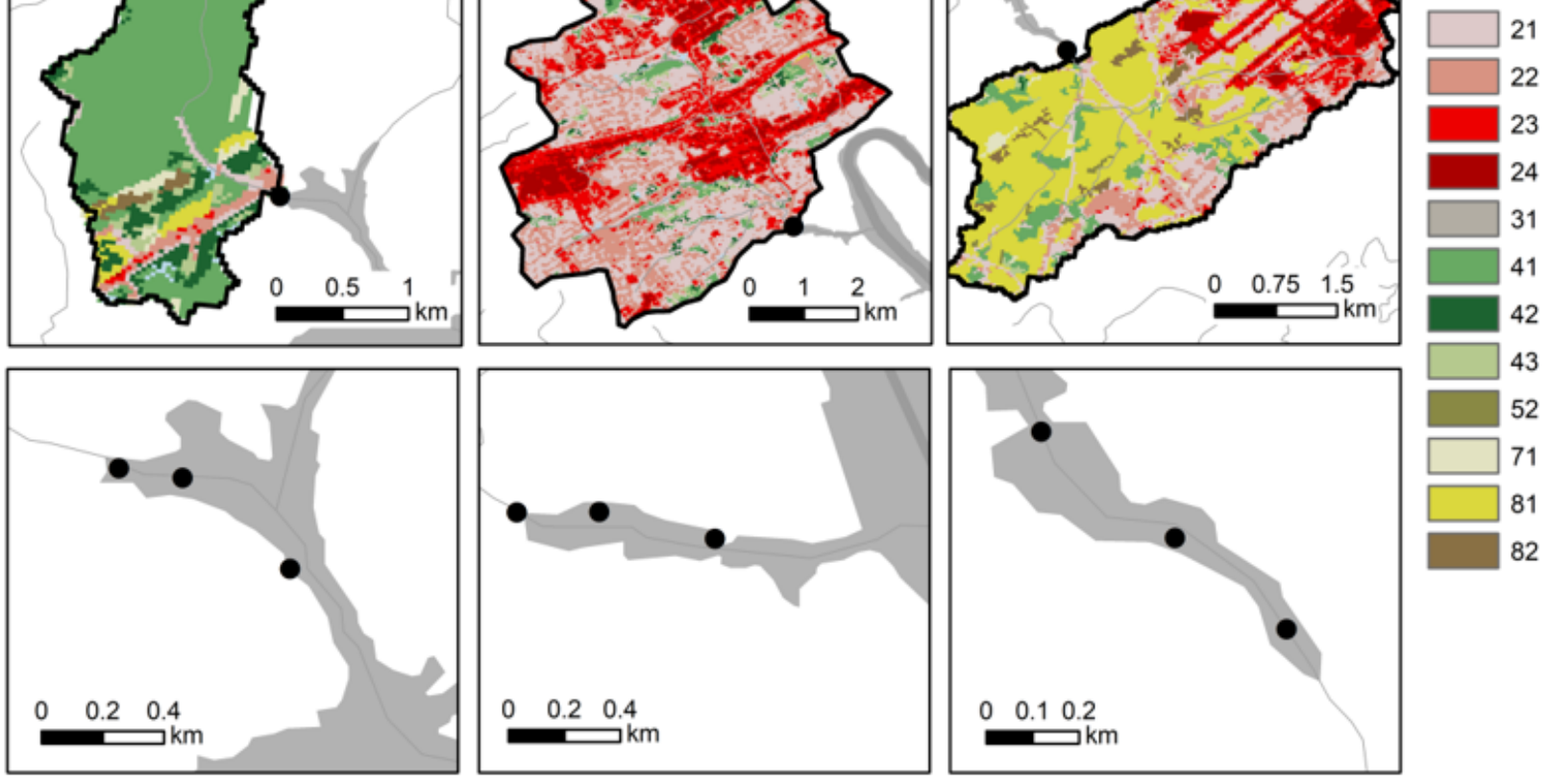

\section{Figure 1}

Locations of reservoir embayments (top), catchments of streams draining into them (middle), and buoy locations within embayments (bottom). Reservoir embayments in this study were located in east Tennessee, USA. Catchments spanned a gradient of urban development. Pink and red shading indicate developed land (NLCD 2011), green shows forest and yellow indicates pasture (full legend of NLCD classes available at: https://www.mrlc.gov/data/legends/national-land-embaymentr-database-2011nlcd2011-legend). Buoy locations within reservoir embayments are indicated by black points. Linear distances between buoys 1 and 2 are $300 \mathrm{~m}$ and between buoys 2 and 3 are $500 \mathrm{~m}$ at each site; we placed buoys in the deepest point at each of these cross-sections. Other site attributes are listed in Table S1. 

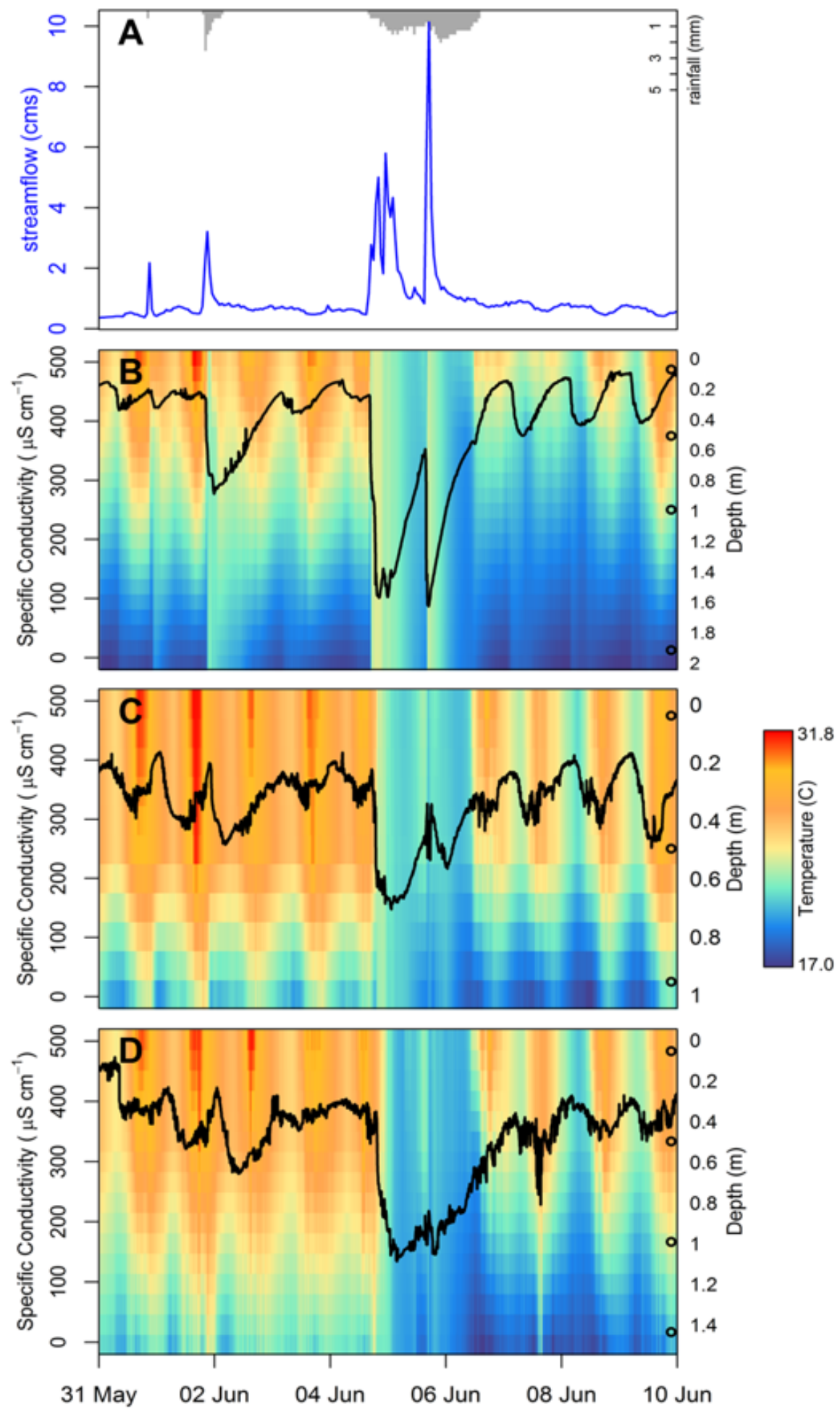

\section{Figure 2}

Example of reservoir storm response for a storm in June 2016 in FC. In the stream (a), rainfall (gray hanging bars) produced flashy discharge peaks (blue). At the buoy 1 (located at the mouth of the stream; b), the incoming stormwater produces three sharp deflections in conductivity (black line) and temporary thermal destratification (temperature interpolated from logger readings - logger locations indicated by open black circles at right). Here, the incoming stormwater pulse is warmer at the onset than later in the 
destratification event. At buoy 2 (300 m "downlake"; c) there is no noticeable thermal or conductivity effect from the initial smaller storms. The temporal variability in temperature during destratification seems to be smoothed, as does the variance in conductivity over the storm. At buoy 3 ( $800 \mathrm{~m}$ total "downlake"; d) thermal destratification and deflection of the background conductivity are still apparent, and further smoothed with respect to the "uplake" signals.

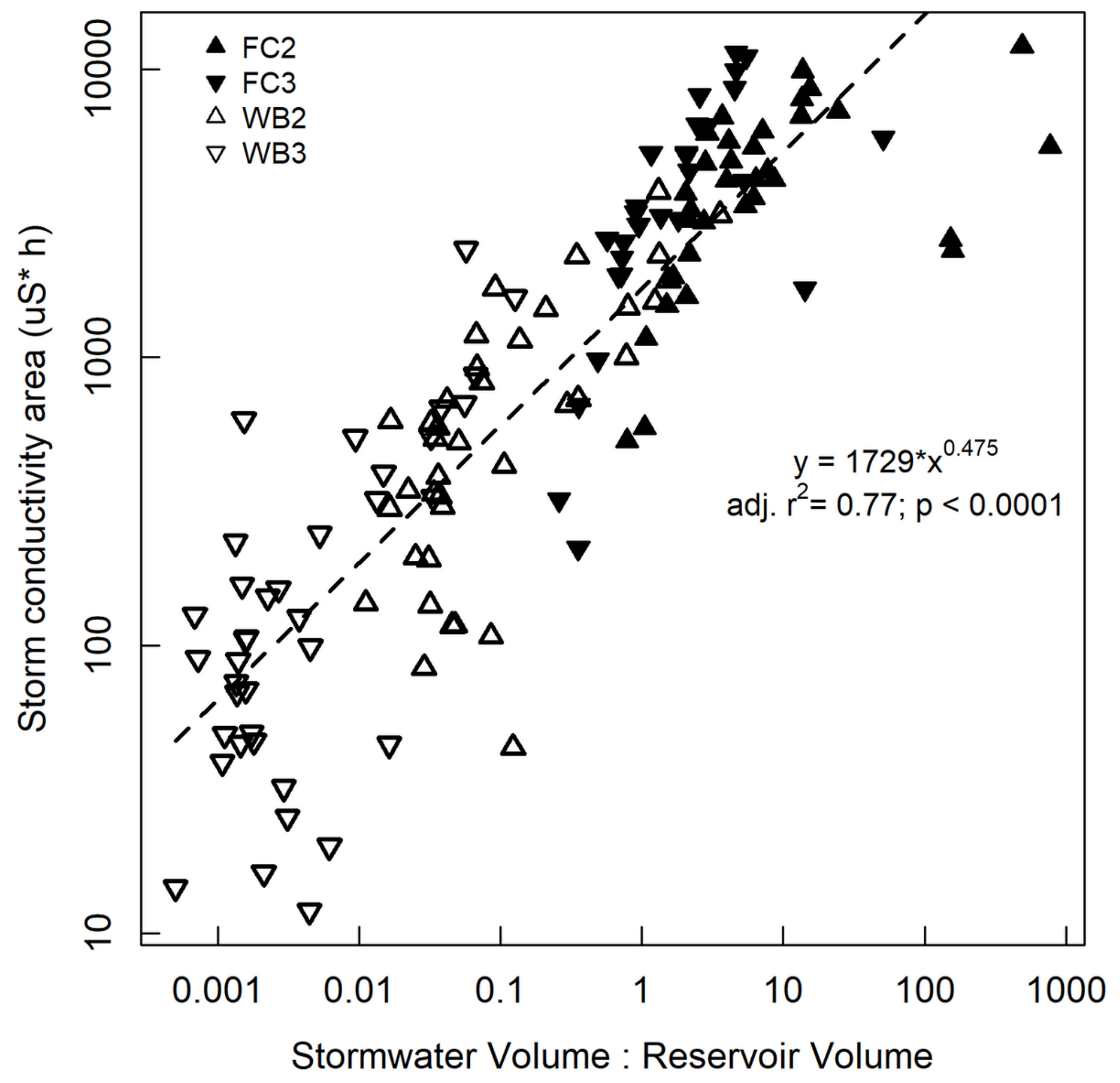

Figure 3 
Storm conductivity area vs. the ratio of incoming stormwater volume to reservoir volume. Storm conductivity area describes the integrated area between the measured conductivity and baseline value (Figure S1). SW:ResVolume is a strong predictor of the storm conductivity area among buoys and explains $77 \%$ of the variation among storms.
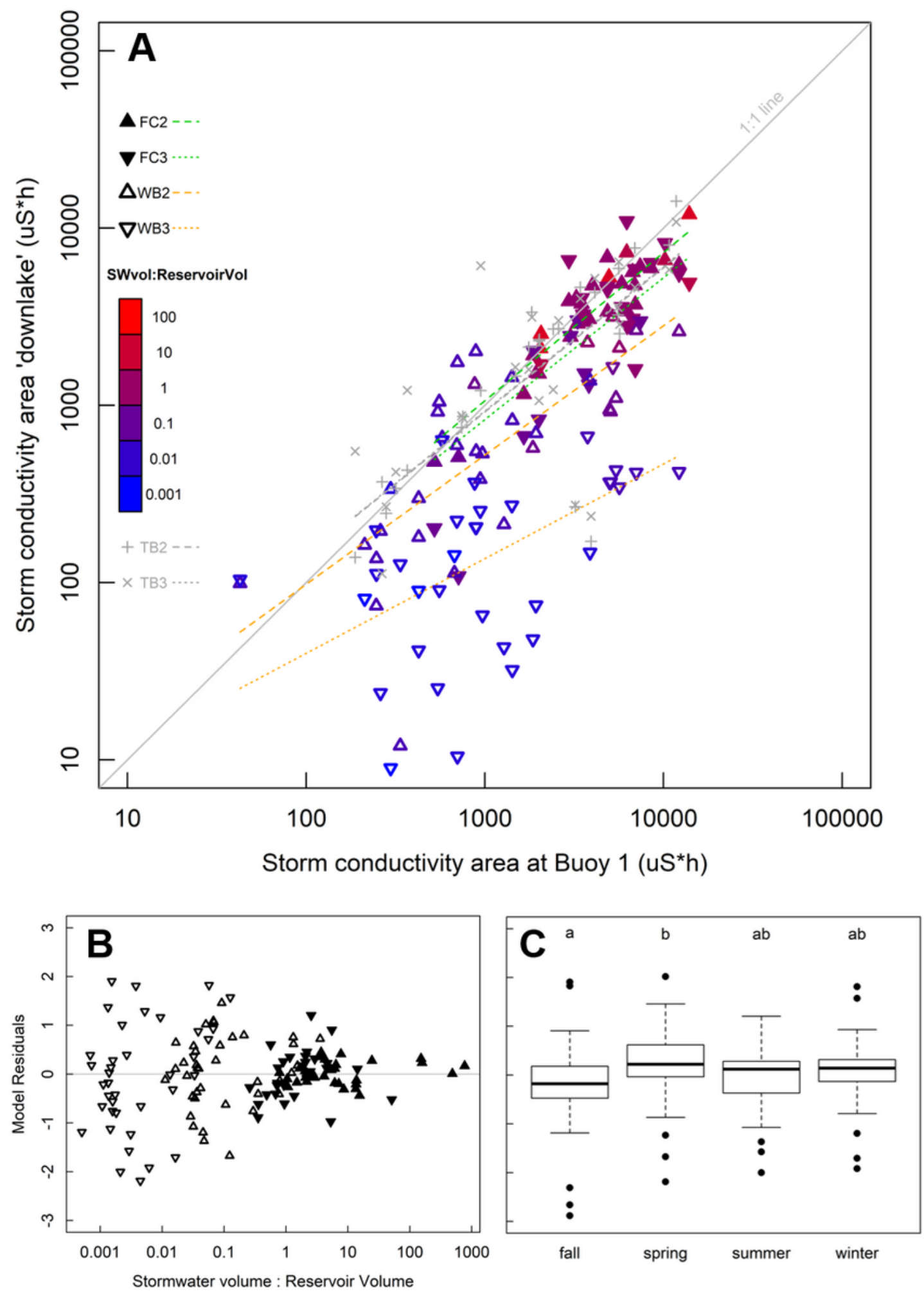

Figure 4 
Storm conductivity area at buoys 2 and 3 vs. at buoy 1 (a). Solid gray line shows a 1:1 relationship (i.e. the signal measured at buoy 1 is the same magnitude as that at 'downlake' buoys). Dashed green, orange, and gray lines show specific slopes and intercepts for each of the 'downlake' buoys as determined by mixed effects model. While the ratio of storm inflow to reservoir volume does not have a significant directional relationship with model residuals (b), the magnitude of residuals is smaller at higher SW:ResVolume ratios. Among seasons, model residuals are significantly higher for storms in spring vs. fall (c). Points show residuals that fall $>1.5 x$ outside the interquartile range.

\section{Supplementary Files}

This is a list of supplementary files associated with this preprint. Click to download.

- Forketal.UESupplementary.docx 